\title{
Cycles of antler and testicular growth in an aseasonal tropical deer (Axis axis)
}

\author{
A. S. I. Loudon and J. D. Curlewis* \\ M.R.C./A.F.R.C. Comparative Physiology Research Group, Institute of Zoology, \\ Zoological Society of London, Regent's Park, London, NWI 4RY, U.K.
}

\begin{abstract}
Summary. Antler and testicular cycles were studied in a group of free ranging axis deer stags kept out of doors in southern England. Within the herd, there was little evidence of a clear seasonal synchrony in the antler cycle. Detailed information obtained from 4 stags indicated that there was a fixed relationship between stage of the antler cycle and testis diameter; minimum testis diameter occurred 1-2 months after antler casting whereas maximum testis diameter occurred when stags were in hard antler. Changes in body weight, circumference of the neck and plasma testosterone concentrations largely paralleled those of testis diameter. Motile spermatozoa were collected at all stages of the testis cycle. Six animals in the early stages of antler growth were selected from the herd in May and 3 of these were implanted with $1 \mathrm{~g}$ melatonin in a Silastic rubber envelope. Each animal was captured on 3 subsequent occasions at monthly intervals. Melatonin was without effect on the rate of increase in size of the testis, circumference of the neck or growth and cleaning of the antlers although 1 of the treated animals failed to cast his antlers at the expected time 8 months after cleaning. We conclude from this study that there is little or no seasonal photoperiodic entrainment of the antler and testicular cycles of males in this population of axis deer.
\end{abstract}

Keywords: circannual cycles; antlers; aseasonal reproduction; axis deer

\section{Introduction}

In seasonally breeding deer from temperate regions the seasonal cycle of rutting behaviour and growth and casting of the antlers is associated with a cycle of growth and secretion of testosterone by the testis (Lincoln, 1971; Lincoln et al., 1972; Bubenik et al., 1975; Leader-Williams, 1979; Sempere \& Biosson, 1981). Photoperiod is the major environmental cue which entrains the seasonal antler cycle (Jaczewski, 1954; Goss, 1969; Pollock, 1975) and more recent work indicates that the effects of photoperiod are mediated by the pineal gland (Plotka et al., 1981; Lincoln, 1985). Further, treatment with the pineal hormone melatonin can disrupt the normal timing of seasonal antler growth in deer (Bubenik 1983; Lincoln et al., 1984). Several species of deer live in the tropical or sub-tropical regions where there are comparatively minor annual changes in photoperiod. For these species there is little information on breeding biology and the antler cycle. In this paper, we describe aspects of the sexual and antler cycle of the male axis deer (Axis axis, a species of the Indian subcontinent) while maintained as a free-ranging herd in the temperate zone and describe the effects of a subcutaneous melatonin implant on antler growth and velvet cleaning.

\section{Materials and Methods}

Animals. The study was carried out with the herd of axis deer living out of doors at Whipsnade Park, Bedfordshire, $51^{\circ} 31^{\prime} \mathrm{N}$. The precise geographical origin of the herd from the Indian subcontinent is unknown and the animals have

*Present address: MRC Reproductive Biology Unit, 37 Chalmers Street, Edinburgh EH3 9EW, U.K. 
been maintained in Britain for over 50 years. The deer were kept in a large grass paddock and offered supplementary hay and concentrates in the winter. Throughout the year, the animals had access to an unheated shelter. The composition of the herd changed during the study but always comprised 10-14 adult males, $12-15$ adult females and $10-15$ calves and sub-adults. Calving in this herd is aseasonal with a similar number of births occurring in the winter and summer months (Kirkwood et al., 1987) although mortality is highly seasonal and calves born in the winter seldom survive (see Table 1).

Table 1. The calving pattern of the axis deer herd at Whipsnade, 1975-1985 (data on season of births from Kirkwood et al., 1987)

\begin{tabular}{lcccccccccccc}
\hline & $\mathrm{J}$ & $\mathrm{F}$ & $\mathrm{M}$ & $\mathrm{A}$ & $\mathrm{M}$ & $\mathrm{J}$ & $\mathrm{J}$ & $\mathrm{A}$ & $\mathrm{S}$ & $\mathrm{O}$ & $\mathrm{N}$ & $\mathrm{D}$ \\
\hline $\begin{array}{l}\text { No. born } \\
\begin{array}{l}\text { No. dying in the first month } \\
\text { of life }\end{array}\end{array}$ & 14 & 10 & 11 & 18 & 6 & 7 & 10 & 12 & 12 & 12 & 13 & 10 \\
\hline
\end{tabular}

Antler cycles within the herd. To obtain further information about the antler cycle, the herd was checked once every 2 weeks from January 1985 to September 1986 and records made of antler state (velvet, cleaning, hard antler or cast) of all adult stags.

Antler and reproductive cycles. Observations were made on 4 adult stags from September 1983 to October 1984. Each animal was captured at 4-weekly intervals using a capture rifle loaded with a dart containing $3 \mathrm{mg}$ etorphine hydrochloride in a $1.5 \mathrm{ml}$ volume and $10 \mathrm{mg}$ acepromazine (Immobilon: C-Vet, Bury St Edmonds, Suffolk, U.K.). Sedations were reversed using an equivalent dose of diprenorphine (Revivon: C-Vet). Immediately after immobilization, blood was collected by venepuncture and measurements were made of testis diameter and length, neck circumference, antler state and body weight. Testicular volumes were calculated using the formula, $V=1 / 6 \pi \mathrm{W}^{2} \mathrm{~L}$, where $\mathrm{V}=$ volume in $\mathrm{ml}, \mathrm{W}=$ mean testicular diameter and $\mathrm{L}=$ length in $\mathrm{cm}$. On a number of occasions, attempts were made to electroejaculate sedated stags with a $2.5 \times 30 \mathrm{~cm}$ rectal probe with two lateral strip electrodes and a portable battery-powered stimulator operating at 20-80 cycles and 2-12 V. Immediately after collection, spermatozoa were treated with BWW diluent (Biggers et al., 1971) and maintained at $20-30^{\circ} \mathrm{C}$ for $2-4 \mathrm{~h}$. Spermatozoa were scored for motility, live/dead ratio and concentration using a haemocytometer.

Histology of the testis and epididymis. Two stags were culled from the herd in May and October 1986. These 2 animals were judged to be at the nadir and peak of their testis cycle ( 65 days after casting and 80 days after velvet cleaning respectively). The testes were fixed in Bouin's fluid ( 20 times volume of the tissue) for $48 \mathrm{~h}$ and then processed to paraffin wax. Sections of $5 \mu \mathrm{m}$ were cut on a Leitz rotary microtome and stained by Heidenhain's iron haematoxylin technique, counterstained with van Gieson's picro-fuchsin. Mean tubule diameter was derived from measurements of tubular cross-sectional area, performed by image analysis (using a System 3, Analytical Measuring System, Saffron Waldon, Essex, U.K.) of the circular profile of 20 tubules selected at random from each testis. The relative stage of the spermatogenic cycle was assessed using criteria established by Holt (1977).

Effect of melatonin on the antler cycle. In May 1985, 6 stags were selected from the main herd for a study of the effects of melatonin on antler growth and cleaning. All 6 animals were adult and had antlers that were in an early stage of growth and at a similar relative stage of development to red deer at this time of year (Lincoln, 1971). Three animals were sedated in May 1985 and received subcutaneous Silastic rubber implants $(500-1$ sheeting, $0.013 \mathrm{~cm}$ thickness, surface area $36 \mathrm{~cm}^{2}$; Dow Corning, Midland, MI, U.S.A.) containing $1 \mathrm{~g}$ melatonin (Sigma Chemicals, Poole, Dorset, U.K.). Three control animals were also sedated, but did not receive implants. On 3 subsequent occasions at intervals of 4 weeks between 08:00 and 10:00 h from June to August 1985 all 6 animals were captured, blood was collected and the measurements described above were carried out. No attempt was made to collect semen. Implants were removed from the animals in October and November 1985.

Hormone determinations. Plasma testosterone was extracted with 10 volumes of diethyl ether and testosterone concentration was measured by radioimmunoassay using antiserum raised in sheep against a testosterone-3-carboxymethyloxime-bovine serum albumin conjugate. The antiserum (No. 505) was supplied by the MRC Reproductive Biology Unit, Edinburgh, and a detailed description of its preparation and use appears elsewhere (Webb et al., 1985). Tritiated testosterone $\left(\left[1,2,6,7-{ }^{3} \mathrm{H}\right] ;\right.$ sp. act. $\left.82 \mathrm{Ci} / \mathrm{mmol}\right)$ was supplied by Amersham International, Amersham, Berks., U.K. Testosterone standard (Sigma Chemical Co., St Louis, MO, U.S.A.) was added at concentrations of $6.25-400 \mathrm{pg} /$ tube. Free and bound testosterone were separated using charcoal-dextran. The antiserum bound $36 \%$ of the labelled testosterone at a final dilution of $1: 127000$ and $50 \%$ of the bound label was displaced by $46 \mathrm{pg}$ testosterone standard. Sensitivity, defined as the first point on the standard curve significantly different from zero binding, was $6.25 \mathrm{pg} /$ tube $(0.3 \mathrm{ng} / \mathrm{ml}$ plasma). Cross-reactivity at $50 \%$ displacement was as follows: $5 \alpha$-dihydroxytestosterone, $42 \%$; androstenedione, $5.6 \%$; progesterone, $0.4 \%$; oestradiol- $17 \beta, 0.4 \%$; androstanediol, $0.3 \%$, and androsterone, $<0 \cdot 1 \%$. 
Recovery of $\left[{ }^{3} \mathrm{H}\right]$ testosterone added to plasma was determined for each assay and all samples were corrected for these losses. Mean recovery over 4 assays was $81.5 \%$ ( $\pm 1 \%$, s.e.m.). Serial dilution of plasma from 4 animals showed parallelism with testosterone standards. To assess the accuracy of the assay, testosterone $(0.5-4 \mathrm{ng} / \mathrm{ml} \mathrm{plasma)} \mathrm{was}$ added to plasma with a low testosterone concentration as measured by radioimmunoassay. Recovery of added testosterone was $76.7 \%( \pm 5 \%)$. The intra-assay coefficient of variation was estimated by measurement $(n=8)$ of testosterone concentration in plasma samples containing $7 \cdot 1$ and $1 \cdot 1 \mathrm{ng} / \mathrm{ml}$ of testosterone and was 3.6 and $4.9 \%$ respectively. The interassay coefficient of variation for the same levels of testosterone in 5 assays was $6 \cdot 1$ and $9 \cdot 2 \%$ respectively. Plasma melatonin concentrations were determined according to the method originally described by Fraser et al. (1983) and subsequently modified by Webley $e t$ al. (1985). The sensitivity of the assay was $10 \mathrm{pg} / \mathrm{ml}$ and the intra-assay coefficient of variation was $4 \cdot 1 \%$.

\section{Results}

\section{Antler cycles within the herd}

The antler cycles of all adult males in the herd are shown in Fig. 1. Of the 3 animals for which 2 consecutive casting dates were obtained, the mean interval from casting to casting based on 2-week observations was 53 weeks (range 45-60 weeks); in 2 animals for which consecutive cleaning dates were available, the mean interval was $49 \cdot 5$ weeks. In 7 animals, the duration of the hard antler phase was $30 \cdot 2$ weeks (range 23-37 weeks), while in 7 animals, the interval from the casting of the old antler to the cleaning of the velvet from the new antler was 25.5 weeks (range 17-30 weeks). Of the 4 stags (Nos 8-11) studied in detail over 1983-84, cleaning of the velvet occurred in January, March, June and July. The remaining stags in the herd cleaned their antlers in the winter or summer months with most animals cleaning between May and September. Several of the stags which cleaned velvet in the winter months were observed to carry the remnants of dead and dying velvet from their antlers for considerable periods and in these animals precise estimates of cleaning date are therefore difficult to assess. None of the animals in the herd was observed to show any seasonal change in the colour or form of coat.

\section{Antler and reproductive cycle}

Data on changes in testosterone concentration, testicular diameter, neck girth and body weight in relation to the antler cycles of 4 stags are shown in Fig. 2. Since each antler cycle was out of phase, with casting in September, October, December and January, the data have been normalized around the time of antler casting. An example of an individual antler cycle from one stag is shown in Fig. 3. In all animals, there were marked fluctuations in testis size with mean testis diameter ranging from a minimum of $231.6 \mathrm{~mm}( \pm 1 \cdot 0$, s.e.m.) to a maximum of $42.6 \mathrm{~mm}( \pm 1 \cdot 2$, s.e.m.). Estimated mean maximum and mean minimum testis volumes were $87.2 \mathrm{ml}( \pm 6.6)$ and $17.8 \mathrm{ml}$ $( \pm 1 \cdot 8)$ respectively. In all animals there was a fixed relationship between stage of the antler cycle and testis size; minimum testis diameter occurred 1-2 months after antler casting whereas maximum testis diameter occurred when stags were in hard antler. Maximum antler growth rate $(0.75 \mathrm{~cm} /$ day $)$ occurred 1 month after the shedding of the old antler. Plasma testosterone concentrations were largely non-detectable during the period of antler growth but, coincicent with the period of hard antler and large testis size, testosterone concentrations above non-detectable levels were frequently observed. None of the stags developed a mane of hair at any stage of the testis cycle.

The body weights and neck circumference of these animals changed in association with the testis cycle rather than the time of year. The period of decline in the volume of the testis was associated with a steep and significant decline in the body weight of the stag (maximum mean $v s$ minimum mean body weight; $t=6.5, P<0.01$ ). The maximum mean body weight for the 4 stags was $110.5( \pm 1.9) \mathrm{kg}$ and in each case was achieved 3-4 months before antler casting. Minimum mean body weight occurred during the middle of the antler growth phase and was $88 \cdot 7( \pm 1 \cdot 3) \mathrm{kg}$, some $21.7 \mathrm{~kg}$ lower than maximum weight. Partial correlation of body weight, testis diameter and 

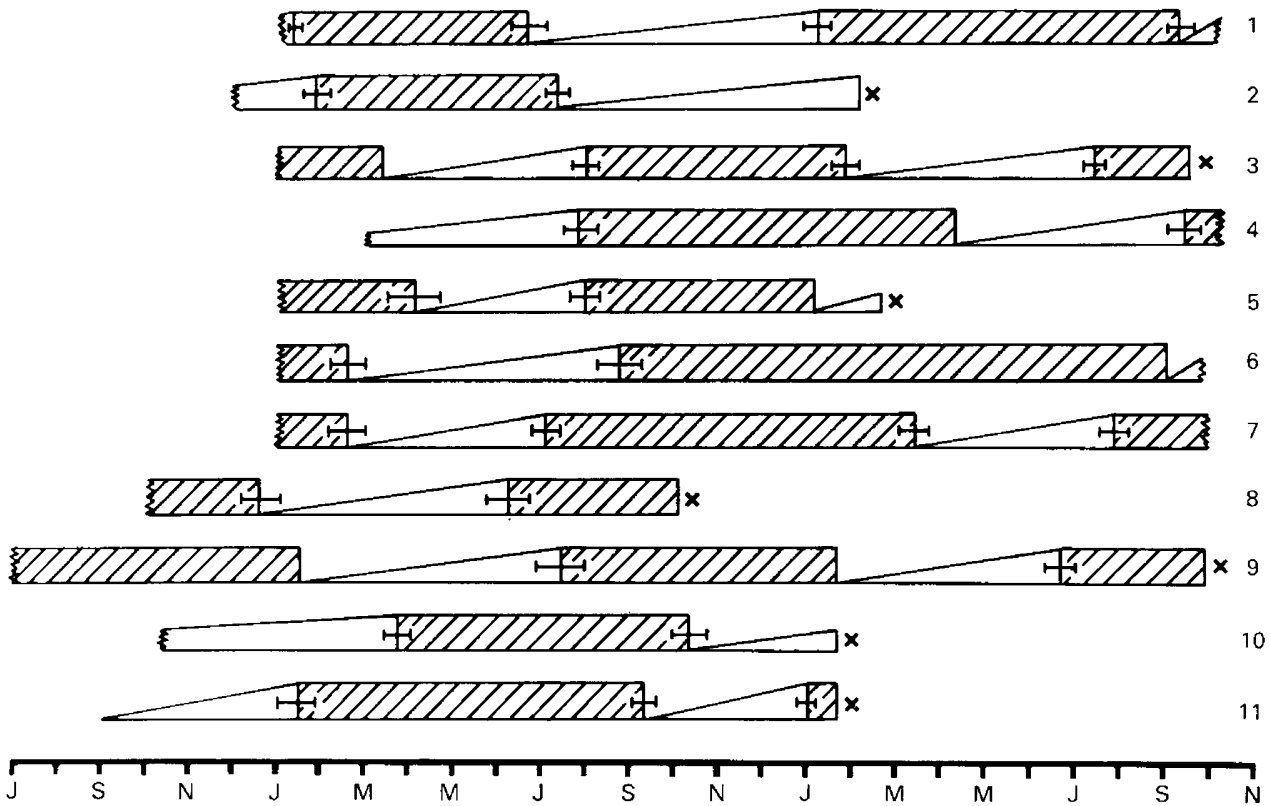

Fig. 1. Cycles of antler growth for 11 adult stags over a 2-year period. Stags 8-11 are described in more detail in Figs 2 and 3. Stags 5-7 received melatonin implants in May 1985. Implants were removed 5-6 months later. Stags 1-7 were studied from January 1985 to October 1986; Stags 8-11 were studied from July 1983 to October 1985 . Horizontal bars indicate ranges of transition to velvet (open areas) or hard horn (cross-hatched areas). Cross indicates the death of an animal.

neck circumference showed that neck circumference was significantly associated with changes in testis diameter $(t=2 \cdot 28, P<0.05)$ and not with body weight $(t=2 \cdot 18, P>0.05)$.

Motile spermatozoa were ejaculated at all stages of the testis cycle and sperm counts ranged from $2 \times 10^{5}$ to $5 \times 10^{9} \mathrm{ml}$. Although several attempts at electroejaculation were unsuccessful, there was no association of stage of testis cycle with failure to collect semen nor was there a significant correlation between sperm density in the ejaculate and testis volume $\left(r^{2}=0 \cdot 288\right)$. Data on spermatozoa collected by electroejaculation are summarized in Table 2.

\section{Histology of the testis and epididymis}

The 2 animals culled at the nadir and peak of the testis cycle in 1986 showed substantial differences in the histological appearance of the testis and epididymis (Figs $4 \& 5$ ). Mean tubule crosssectional surface area was $16.1( \pm 0.9$ s.e.m. $)$ and $25.8( \pm 1.08) \times 10^{3} \mu^{2}$ and estimated tubule diameter was $163 \cdot 2\left( \pm 5 \cdot 3\right.$ s.e.m.) and $212( \pm 3 \cdot 7) \times 10^{3} \mu \mathrm{m}^{2}$ for the regressed and developed testis respectively. In the regressed state (Fig. 4a), many of the tubules were in an early phase of development with a high proportion showing a reduced lumen, some primary spermatogonia but few elongating spermatids. However, in $10 \%$ of the tubules, there was evidence of active spermatogenesis as indicated by the presence of young unelongated spermatids and an enlarged lumen. These spermatids were all round in shape and were abundant in certain tubules but there were no ignificant numbers of elongating spermatids in any of the tubules examined. In the developed testis Fig. 4b), there was evidence of active spermatogenesis in a large number of the tubules examined, $\checkmark$ ith abundant elongating spermatids and an enlarged lumen to the tubule. Large numbers of ,ermatozoa were present in the epididymides of both stags (Fig. 5). 


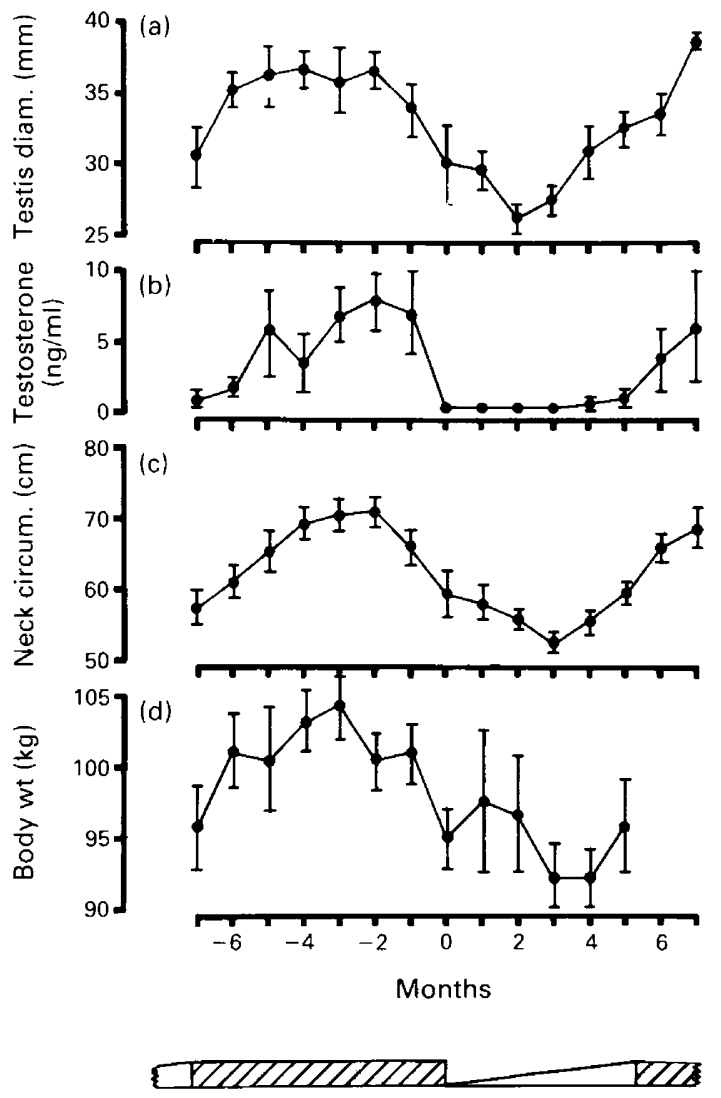

Fig. 2. Changes in testicular diameter (a), testosterone concentration (b), neck circumference (c) and body weight (d) for 4 adult axis deer stags. Data have been normalized for each animal around the time of antler casting. The timing of hard horn (hatched bar) and antler re-growth (open bar) is shown below.

The effect of melatonin on the antler cycle

The melatonin implants produced high concentrations of melatonin in the peripheral plasma. Values measured 1 month after implant insertion were 330,191 and $172 \mathrm{pg} / \mathrm{ml}$ for the 3 treated animals and $<8 \mathrm{pg} / \mathrm{ml}$ for the control animals. Between May and August there were significant increases in testis diameter, circumference of the neck and length of the antlers in both groups (Fig. 6; analysis of variance; $P<0.01)$ but melatonin treatment was without effect $(P>0.05)$. After the removal of the implants between October and December 1985, Stag 6 (Fig. 1), which had received an implant, remained in hard antler for 14 months from July 1985 through to casting on 3 September 1986.

\section{Discussion}

The results presented here indicate that in the axis deer stag the antler cycle is associated with changes in activity of the testis. In all 4 animals studied in detail, testis size reached a nadir shortly after the casting of the old antler and increased gradually during the period of antler growth. 


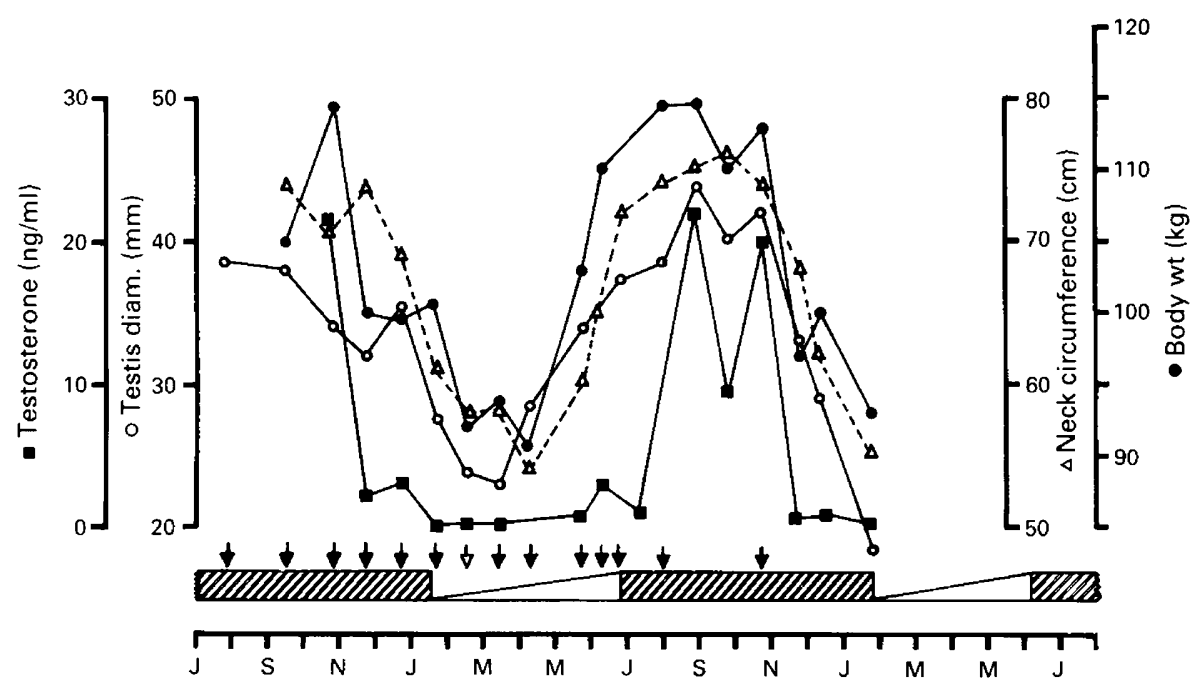

Fig. 3. Seasonal changes in testis diameter $(O)$, plasma testosterone concentration $(\boldsymbol{\square})$, neck circumference $(\triangle)$ and body weight $(\bullet)$ for Stag 9 . The times of electroejaculation are indicated with a vertical arrow, closed arrows indicating success and open arrow failure to produce a semen sample. The antler cycle is indicated as a growth phase (velvet; open) and hard horn (cross-hatched).

Table 2. Data on success of collection by electroejaculation and spermatozoa density and motility at 3 different stages of the antler cycle

\begin{tabular}{lcccc}
\hline & $\begin{array}{c}\text { No. of attempts } \\
\text { to collect semen }\end{array}$ & $\begin{array}{c}\text { No. of times } \\
\text { semen collected }\end{array}$ & $\begin{array}{c}\text { Mean }( \pm \text { s.e.m.) } \\
\text { conc. (no./ml) }\end{array}$ & $\begin{array}{c}\text { Mean motility } \\
\% \text { (range) }\end{array}$ \\
\hline $\begin{array}{l}\text { Antler in velvet } \\
\begin{array}{l}\text { Antler in hard horn } \\
\text { (1st four months) }\end{array}\end{array}$ & 16 & 13 & $8 \cdot 2( \pm 2 \cdot 9) \times 10^{7}$ & $55(0-80)$ \\
$\begin{array}{l}\text { Antler in hard horn } \\
\text { (2nd four months) }\end{array}$ & 15 & 8 & $9 \cdot 6( \pm 6 \cdot 6) \times 10^{7}$ & $63(20-85)$ \\
\hline
\end{tabular}

Maximal testis size occurred 2-3 months after the shedding of the velvet. Thus, in this species, as in seasonally breeding species of deer that live in the temperate zone, there is a close correlation between changes in testicular size, testosterone secretion and the growth and development of the antler (red deer: Lincoln, 1971; Lincoln \& Kay, 1979; white-tailed deer: Mirachi et al., 1975; roe deer: Bramley, 1970; reindeer: Leader-Williams, 1979). In addition, both the circumference of the neck and body weight showed pronounced changes in association with the change in testis size and testosterone secretion with the peak in neck circumference and body weight occurring at the same time as maximal testis size. In this respect, the axis stag is similar to the seasonally breeding red deer stag (Lincoln et al., 1970; Lincoln, 1971; Mitchell et al., 1976).

Successful electroejaculation of motile spermatozoa was achieved both during antler growth and hard antler, despite an estimated 5-fold change in testis volume. Histological evidence from the testis removed during early antler growth indicated that limited spermatogenesis may occur at the nadir of the testis cycle although collection of motile spermatozoa by electroejaculation at all stages of the antler cycle may reflect storage of spermatozoa in the epididymis throughout the period of 

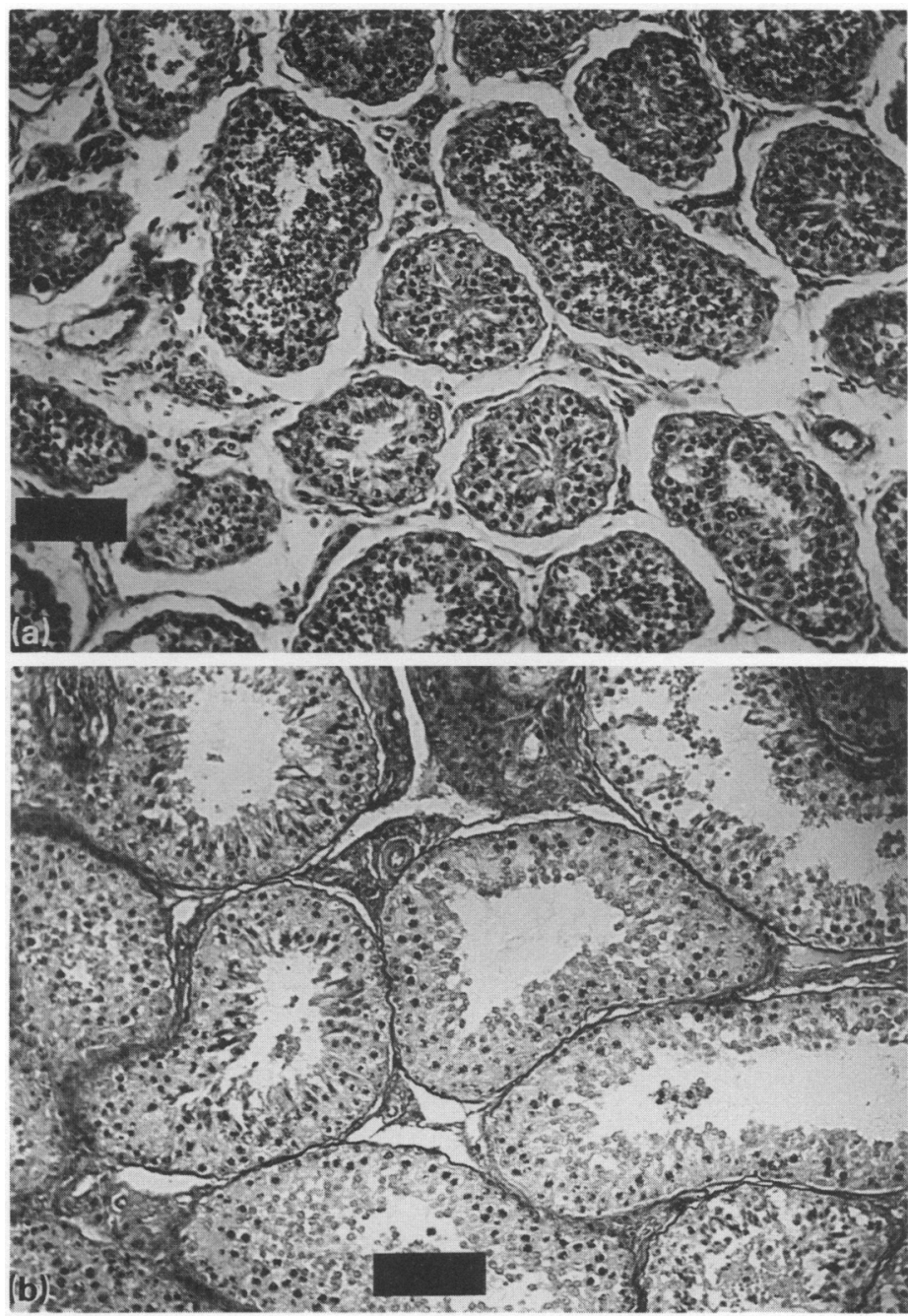

Fig. 4. Seminiferous tubules from the testis of (a) an adult axis stag (Stag 12, not shown in Fig. 1) culled at about the nadir of the cycle in testis size, indicating a reduced lumen volume and the presence of primary spermatogonia, and (b). Stag 3 (adult, see Fig. 1), culled at about the peak of the cycle in testis size, indicating the enlarged lumen and abundant elongating spermatids. Scale bar $=100 \mu \mathrm{m}$.

low spermatogenic activity rather than spermatogenic activity of the testis. In a comparison of the degree of seasonal testicular regression in several species of seasonal deer, Lincoln (1985) suggested that a reduction in testis weight to below $25 \%$ of the seasonal maximum was associated with complete infertility as judged by an arrest in spermatogenesis. In the red deer, seasonal infertility is associated with a significant reduction in Sertoli cell density, stem spermatogonia number and the number of elongating spermatids (Hochereau-de Reviers \& Lincoln, 1978). However, despite a 5fold decline in testis volume, testicular regression in the axis deer is not associated with complete azoospermia. In the herd studied here, females conceive throughout the year; it is not known whether fertile matings can take place with males in velvet or whether only males in hard antler are able to compete for access to females and rut successfully. In the non-herding Reeves' muntjac (Muntjiacus reevesi), births can occur in any month of the year (Zuckerman, 1953; Chapman \& 

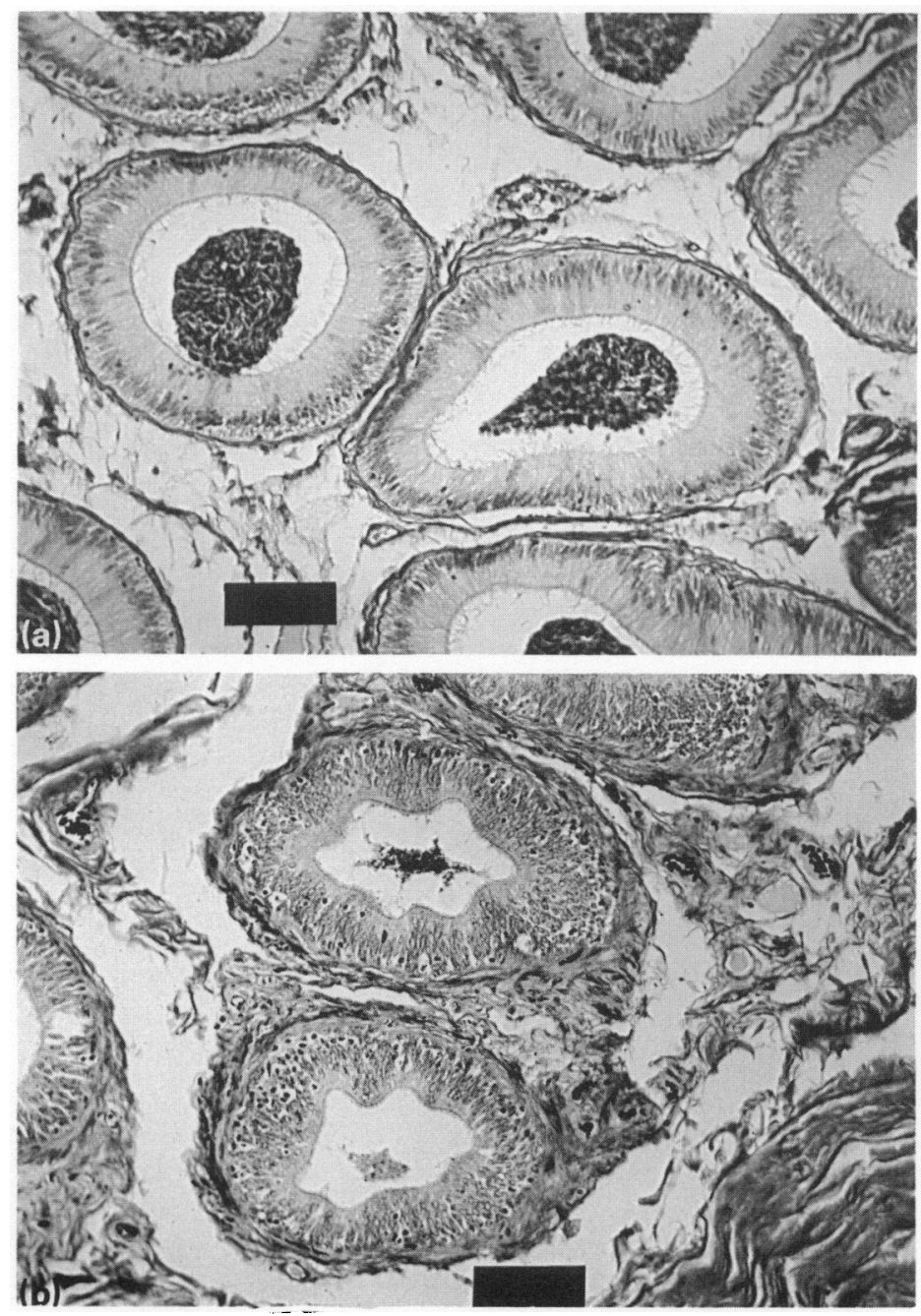

Fig. 5. Proximal epididymis of (a) Stag 12 and (b) Stag 3 indicating the presence of abundant spermatozoa. $\mathrm{Bar}=100 \mu \mathrm{m}$.

Dansie, 1970), but the male exhibits a seasonal antler cycle and is capable of fertile mating while the antlers are at any stage of development (Chapman \& Chapman, 1982).

In the wild, there is a regional variation in the timing of the antler cycle and season of births with axis stags in the north of their range exhibiting a seasonal antler cycle (Schaller, 1967; Mishra, 1982), while in the south of the range there is little synchrony in the antler cycle or birth season (Phillips, 1928; Morris, 1935). Within the axis herd at Whipsnade births occurred throughout the year and the antler cycles of males showed poor synchrony with one another although the majority of animals cleaned their velvet in the summer months. One possible explanation of such synchrony is that seasonal mortality (see Table 1) may synchronize antler cycles since males within the herd would tend to achieve puberty and develop the first antler at a similar time of year. The poor synchrony of antler growth between males suggests that photoperiod is not involved in controlling the antler cycle in this species. This contrasts with seasonally breeding deer in which experimental manipulations of photoperiod can drive the antler cycle (Jaczewski, 1954; Goss, 1969). Since photoperiod manipulation of axis stage was impractical, animals were treated with melatonin as an 

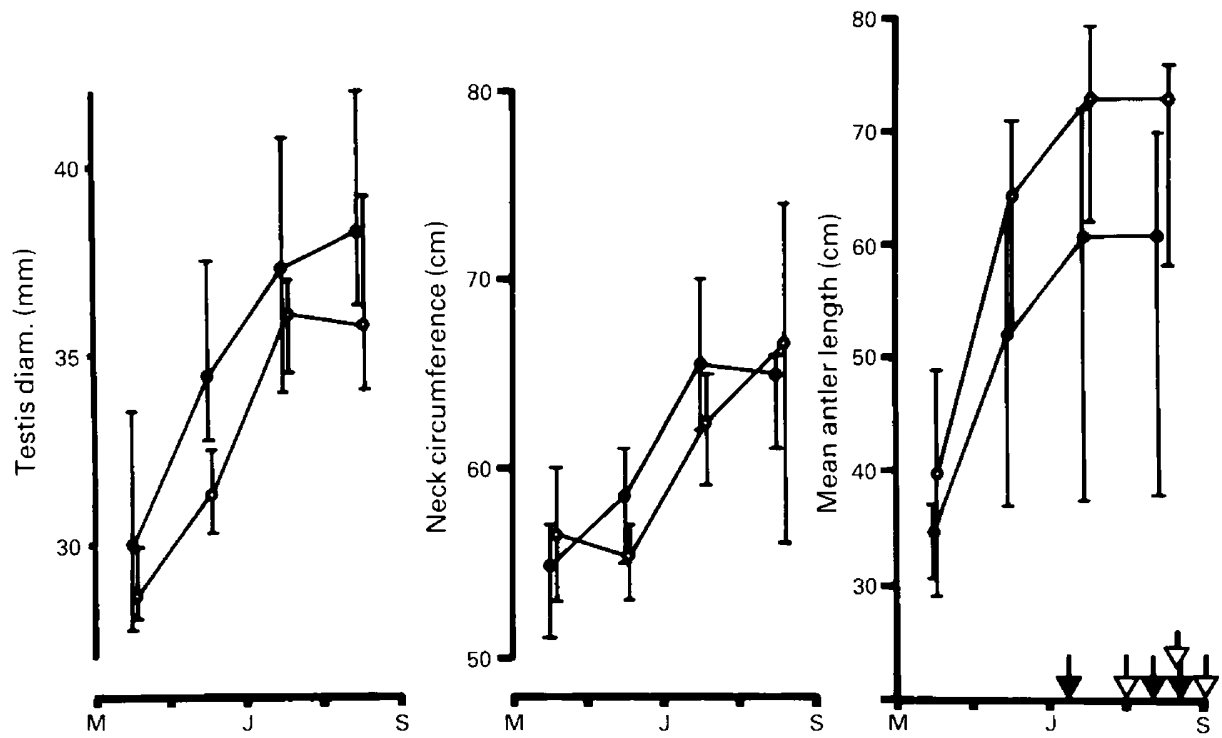

Fig. 6. Changes in testis diameter, neck circumference and antler length for control $(\Theta)$ and melatonin-implanted $(O)$ stags from May to August 1985. The times of shedding of velvet are shown as vertical closed and open arrows for the control and melatonin-treated stags respectively.

alternative. The lack of an effect of melatonin on the growth of the testis and antler contrasts with work on white-tailed deer (Bubenik, 1983) and red deer (Lincoln et al., 1984). Treatment with melatonin either by implant or oral administration $2 \mathrm{~h}$ before dusk significantly advances antler cleaning, testicular redevelopment and testosterone secretion by the testis in these species. Although melatonin failed to hasten the development of the testis and the hard antler in the axis stag, 1 of the 3 treated animals failed to cast at the expected time and remained in hard antler for 14 months after melatonin treatment. Thus, the possibility of long term effects of such melatonin treatments cannot be ignored.

We conclude that, in the sub-tropical axis deer, the photoperiodic-pineal link to the reproductive axis may be absent or only able to entrain the reproductive system weakly. Long-term cyclic changes in testicular activity may occur in the absence of photoperiodic entrainment. The role of photoperiod in other seasonal deer species may therefore be to entrain rather than drive directly seasonal rhythms of reproduction and antler growth.

We thank Alison Beasey, R. Kock and R. Cinderey for their help throughout the course of this work at Whipsnade, Dr H. Moore, Dr W. Holt and Mr D. Spratt for assistance with collection and assessment of semen and the preparation of stained tissue sections; and Dr A. McNeilly for the gift of antiserum.

\section{References}

Biggers, J.D., Whitten, W.K. \& Whittingham, D.G. (1971) The culture of mouse embryos in vitro. In Methods in Mammalian Embryology, pp. 86-116. Ed. J. C. Daniel. Freeman, San Fransisco.

Bramley, P.S. (1970) Territoriality and reproductive behaviour in roe deer. J. Reprod. Fert., Suppl. 11, $43-70$.
Bubenik, G.A. (1983) Shift of seasonal cycle in whitetailed deer by oral administration of melatonin. $J$. exp. Zool. 225, 155-156.

Bubenick, G.A. Bubenik, A., Brown, G.M. \& Wilsr n, D. (1975) The role of sex hormones in the growth of :itler bone tissue. Part 1. Endocrine and metabolic eff : 's s of antiandrogen therapy. J. exp. Zool. 194, 348-35c 
Chapman, D.I. \& Dansie, O. (1970) Reproduction and foetal development in female muntjac deer (Muntjiacus reevesi). Mammalia 34, 303-319.

Chapman, D.I. \& Chapman, N.G. (1982) The antler cycle of the adult Reeves' muntjac. Acta theriol. 27, 107-114.

Fraser, S., Cowen, M., Franklin, C., Franey, J. \& Arendt, J. (1983) Direct radioimmunoassay for melatonin in plasma. Clin. Chem. 29, 396-397.

Goss, R.J. (1969) Photoperiodic control of antler cycles in deer. I Phase shift and frequency changes. J. exp. Zool. 170, $311-324$.

Hochereau-de Reviers, M.T. \& Lincoln, G.A. (1978) Seasonal variation in the testicular histology of the red deer stag (Cervus elaphus). J. Reprod. Fert. 54, 209-213.

Holt, W.V. (1977) Postnatal development of the testis of the cuis, Galea musteloides. Lab. Anim. 11, 87-91.

Jaczewski, Z. (1954) The effect of changes in the length of daylength on the growth of antlers in deer (Cervus elaphus). Folia Biol. 2, 133-137.

Kirkwood, J.K., Gaskin, C.D. \& Markham, J. (1987) Perinatal mortality and season of birth in captive wild ungulates. Vet. Rec. 120, 386-390.

Leader-Williams, N. (1979) Age related changes in the testicular and antler cycles of reindeer, Rangifer tarandus. J. Reprod. Fert. 57, 117-126.

Lincoln, G.A. (1971) The seasonal reproductive changes in the Red deer stag (Cervus elaphus). J. Zool., Lond. 163, 105-123.

Lincoln, G.A. (1985) Seasonal breeding in deer. Bull. Roy. Soc. N.Z. 22, 165-179.

Lincoln, G.A. \& Kay, R.N.B. (1979) Effect of season on the secretion of testosterone in intact and castrated red deer stags (Cervus elaphus). $J$. Reprod. Fert. 55, $75-80$.

Lincoln, G.A., Youngson, R.W. \& Short, R.V. (1970) The social and sexual behaviour of the red deer stag. $J$. Reprod. Fert., Suppl. 11, 71-103.

Lincoln, G.A., Guinness, F. \& Short, R.V. (1972) The way in which testosterone controls the social and sexual behaviour of the red deer stag (Cervus elaphus). Horm. Behav. 3, 375-396.

Lincoln, G.A., Fraser, H.M. \& Fletcher, T.J. (1984) Induction of early rutting in male red deer (Cervus elaphus) by melatonin and its dependence on LHRH. J. Reprod. Fert. 72, 339-343.
Mirachi, R.E., Scanlon, P.F., Kirkpatrick, R.L. \& Schrek, C.B. (1975) Variation in androgen level in white-tailed deer in relation to the antler cycle and breeding season. J. Anim. Sci. 40, 185-191.

Mishra, H.R. (1982) The ecology and behaviour of chital (Axis axis) in the Royal Chitwan National Park, Nepal, with comparative studies of Hog deer (Axis porcinus), sambar (Cervus unicolor) and barking deer (Muntjiacus muntjak). Ph.D. thesis, University of Edinburgh.

Mitchell, B., McCowan, D. \& Nicholson, I.A. (1976) Annual cycles of body weight and condition in Scottish red deer. J. Zool., Lond. 180, 107-127.

Morris, R.C. (1935) Growth and shedding of antlers in sambar (Cervus unicolor) and cheetal (Axis axis) in south India. J. Bombay Nat. Hist. Soc. 37, 484.

Phillips, W.W.A. (1928) A guide to the mammals of Ceylon. Spolia Zeylanica 14, 1-50.

Plotka, E.D., Seal, U.S., Letellier, L.J., Verme, L.J. \& Ozaga, J.J. (1981) Effects of pinealectomy on seasonal phenotypic changes in white-tailed deer (Odocoileus virginialis borealis). In Pineal Function pp. 45-56. Eds C. D. Matthews \& R. F. Seamark. Elsevier/North Holland, Amsterdam.

Pollock, A.M. (1975) Seasonal changes in appetite and sexual condition in red deer stags maintained on a six month photoperiod. J. Physiol., Lond. 224, 95-96.

Schaller, G.B. (1967) The Deer and the Tiger. University of Chicago Press, Chicago.

Sempere, A.J. \& Biosson, J. (1981) Relationship between antler development and plasma androgen concentrations in adult roe deer (Capreolus capreolus). $J$. Reprod. Fert. 62, 49-63.

Webb, R., Baxter, G., McBride, D., Nordblom, G.D. \& Shaw, M.P.K. (1985) The measurement of testosterone and oestradiol-17 $\beta$ using iodinated tracers and incorporating an affinity chromatography extraction procedure. J. Steroid Biochem. 23, 1043-1051.

Webley, G.E., Mehl, H. \& Willey, K.P. (1985) Validation of a sensitive direct assay for melatonin for investigation of circadian rhythms in different species. $J$. Endocr. 106, 387-394.

Zuckerman, S. (1953) The breeding season of mammals in captivity. Proc. zool. Soc. Lond. 122, 827-950.

Received 26 October 1987 